\title{
The effects of overtraining on a reversal and nonreversal shift'
}

SIDNEY H. HOCHMAN

QUEENS COLLEGE OF THE CITY UNIVERSITY OF NEW YORK

Children, 12-13 years old, were given criterion or overtraining on a modified card sorting test, then transferred to a reversal or nonreversal shift. Type of shift was found to be significant, while degree of training had no significant effect. While the results of reversal ease are interpreted in terms of the operation of a dimension-specific mediator, the failure to find an ORE is accounted for in terms of the S's age, motivation, as well as prior experience in learning tasks.

The weight of the published evidence seems to indicate that there is a direct relation between degree of overlearning and the ease of learning a new antagonistic task. It has been shown (Reid, 1953; Pubols, 1956; Capaldi \& Stevenson, 1957; Brookshire, Warren, \& Ball, 1961; D'Amato \& Jagoda, 1961; Mackintosh, 1962; Capaldi, 1963; Mackintosh, 1963) that if rats are overtrained on a simple discrimination problem, they learn the reversal of the discrimination in fewer trials than rats not so overtrained.

One type of explanation offered to explain the ORE (overlearning reversal effect), put forward by Goodwin \& Lawrence (1955), suggests that in any discrimination, two learning processes are involved. One would involve the identification of and reaction to a dimension or set of stimuli, and the second would involve the establishment of preferences to stimuli within a set. The better the first process is learned (as a result of overtraining), the more likely the Ss are to keep on responding to the relevant cues after reversal, the less likely they are to respond to irrelevant cues, and the faster they will learn the reversal.

For example, if one group of children is trained to respond to a brightness dimension, various amounts of overtraining being given, and a second group trained on a number dimension, various amounts of overtraining being given, and subsequently the first group reversed on the brightness dimension (reversal), while the second group is made to learn an entirely different discrimination (nonreversal), the Goodwin and Lawrence hypothesis would make the following differential prediction: overtraining will only facilitate the learning of the reversal, while overtraining on the number discrimination will actually hinder the learning of a discrimination in which a number difference is irrelevantsince the more firmly the number dimension is learned, the longer it will take to extinguish, and successful learning of the second discrimination cannotoccur until the number dimension is extinguished, and the appropriate dimension learned.

\section{Method}

Subjects. The Ss were 48 seventh-grade students ranging in age from 12-13 years, drawn randomly from a Queens' public school.

Apparatus. Cards from the Wisconsin Card Sorting Test were used. All cards differed in color (red vs. green), in figure (cross vs. circle), and in number (one vs. two, Series I; three vs. four, Series II).

Procedure. The Ss were obtained from the classroom and were brought to the testing room. Testing was done individually and began with the general instructions that $S$ was to play a game, the object of which was "to be correct." Each $\mathrm{S}$ was then read the following:

You will be shown a series of sets of two cards. One of these cards, and only one, in each of the sets is correct. The idea for you is to find out which one is correct. You must point to the one you feel is correct. Decide as best you can. If you are correct, I will say, "correct;" if not, I'll say, "incorrect."

The design was a 2 by 3 factorial consisting of Reversal (C-RC), Nonreversal (N-RC) shifts, Criterion, 10-overlearning, and 20-overlearning trials. For the C-RC group, Series I involved their learning "red" as the correct response. For the N-RC group, Series I involved their learning "one" as the correct response. The transfer trials (Series II) began, without informing the Ss of the change in the set of cards, after Ss reached the criterion of five consecutive correct responses, after 10 overtraining trials, or after 20 overtraining trials. "Green" was now correct for the C-RC group as well as the N-RC group. There were eight Ss per cell. (See Table 1.)

Resulfs

Mean trials to criterion on Series I and Series II for groups $\mathrm{C}-\mathrm{RC}$ and $\mathrm{N}-\mathrm{RC}$ are presented in Table 2. Analysis of variance for independent groups for Series I yielded an $\mathrm{F}$ ratio which was not significant.

However, analysis of variance for Series II reveals a significant difference only for the reversal vs. nonreversal shifts $(F=78.42, \mathrm{df}=1 / 42, \mathrm{p}<.001)$. No signif-

Table 1. Experimental Design

\begin{tabular}{llr} 
Groups & Series I & Series II \\
\hline reverse (C-RC) & R1,R1 G1,G2 & G3,G4 R3, R4 \\
nonrev. (N-RC) & R1,G1 R2,G2 & G3, G4 R3,R4 \\
\hline
\end{tabular}

$R 1=$ cards with one red figare:

$\mathrm{G} 2=$ cards with two green figures, etc. 
Table 2. Mean Number Trials to Criterion

\begin{tabular}{lllllll} 
& Series I & & \multicolumn{5}{c}{ Series II } \\
& Crit. & 10 ov. & 20 ov. & Crit. & 10 ov. & 20 ov. \\
\hline C-RC & 3.75 & 4.25 & 3.50 & 1.25 & 1.375 & 1.125 \\
N-RC & 3.50 & 3.375 & 3.75 & 7.25 & 10.75 & 9.125 \\
\hline
\end{tabular}

icant interaction effect between degree of training and type of transfer task was found, nor were any differences found in the effect of degree of training.

\section{Discussion}

Regarding the hypothesis that in learning a discrimination two processes are involved, the results are in agreement with Goodwin and Lawrence, as well as the findings of Furth \& Youniss (1964). The relative ease of mastering the reversal as well as the difficulty experienced in mastering the nonreversal, irrespective of the degree of training, indicates the operation of a dimension-specific mediator. When presented with novel stimuli (Series II), all Ss proceeded to respond along the dimension of their previously established associations.

However, consistent with the results and the interpretation of Stevenson \& Weir (1959), the failure to find performance differences according to degree of training may very easily be attributed to the type of $S$ used. On the basis of prior experience, bright children may very well have learned that regardless of the number of times they have been reinforced, withdrawal of reinforcement should be followed by an attempt to find other solutions. Further, since motivation was kept high throughout the experiment, as all children appeared to enjoy the task, it may be hypothesized that overtraining reduces effectiveness of performance when it results in monotony and decreased drive. Keeping motivation high would seem to reduce the effects of overtraining.

\section{References}

Brookshire, K. H., Warren, J. M., \& Ball, G. G. Reversal and transfer learning following overtraining in rat and chicken. $J$. comp. physiol. Psychol, 1961, 54, 98-102.

Capaldi, E. J. Overlearning reversal effect in a spatial discrimination task. Percep. mot. Skills, 1963, 16, 335-336.

Capaldi, E. J., \& Stevenson, H. W. Response reversal following different amounts of overtraining. J. comp. physiol. Psychol., 1957, 50, 195-198.

D'Amato, M. R., \& Jagoda, H. Analysis of the role of overlearning in discrimination reversal. J. exp. Psychol., 1961, 61, 55-60.

Furth, H. G., \& Youniss, J. Effect of overtraining on three discrimination shifts in children. J. comp. physiol. Psychol., 1964, 57, 290-293.

Goodwin, W. R., \& Lawrence, D. H. The functional independence of two discrimination habits associated with a constant stimulus situation. J. comp. physiol. Psychol., 1955, 48, 437-443.

Mackintosh, N. J. The effects of overtraining on a reversal and a nonreversal shift. J. comp. physiol. Psychol., 1962, 55, 555-559.

Mackintosh, N. J. Extinction of a discrimination habit as a function of overtraining. J. comp. physiol. Psychol., 1963, 56, 842847 .

Pubols, B. H. Jr. The facilitation of visual and spatial discrimination reversal by overlearning. J. comp. physiol. Psychol., 1956 , $49,243-248$.

Reid, L. S. The development of noncontinuity behavior through continuity learning. $J$. exp. Psychol., 1963, 46, 107-112.

Stevenson, H. W., \& Weir, M. W. Response shift as a function of overtraining and delay. J. comp. physiol. Psychol., 1959, 52. 327-329.

\section{Note}

1. The author is grateful to Dr. William F. Reynolds for his suggestions and criticisms.
Continued from page 234 .

Harcum and Coppage(p. 572) also state that we believe an intertrial gap is necessary for the serial position effect. This is not our view despite the title and emphasis of our report. Our discussion about the difference between $E_{1}$ and $E_{2}$ with respect to primacy and the presence of idiosyncratic primacy effects in $E_{2}$ would make no sense if this were the case. The intertrial interval only serves, after the first trial, to enhance the discriminability of the ends of the list.

\section{References}

Breckenridge, K., Hakes, D. $\boldsymbol{T}$., \& Young, R. K. Serial learning in a continuous serial list. Psychon. Sci., 1965, 3, 139-140.

Eysenck, H. J. Serial position effects in nonsense syllable learning as a function of interlist rest pauses. Brit. J. Psychol., $1959,50,360-362$.

Glanzer, M., \& Peters, S. C. Re-examination of the serial position effect. J. exp. Psychol., 1962, 64, 258-266.

Harcum, E. R., \& Coppage, E. W. Serial learning without primacy or recency effects. Psychon. Sci., 1965, 3, 571-572.

Keppel, G. Comments on the hypothesis of implicit serial-position cues. Psychon. Sci, 1965, 3, 471-472.

Lippman, L. G., \& Denny, M. R. Serial position effect as a function intertrial interval. $J$. verbal Learn. verbal Behav., 1964, 3. 496-501. 